\title{
The use of multiple representation for math education
}

Yusuf Tayfun Tepedeldiren $\mathrm{a}^{*}$

Tahsin Dizren ${ }^{b}$

Tugsan Soltan ${ }^{\mathrm{c}}$

Melike Yagmur Tepedeldiren ${ }^{d}$

Suggested Citation:

New Trends and Issues Proceedings on Humanities and Social Sciences.

Abstract 


\section{Introduction}

\section{Methodology}

\subsection{The main elements of conditional forms}

$\perp$

\subsection{The evaluation of the conditional forms}

(a)

$$
\left\{\begin{array}{l}
e \text { if the proposition } p \text { is true } \\
\uparrow \text { if the proposition } p \text { is false } \\
\perp \text { for other all situations }
\end{array}\right.
$$

(b)

$$
\left\{\begin{array}{c}
e_{1} \quad \text { if the proposition } p_{1} \text { is True } \\
\left(p_{2} \rightarrow e_{2}, \ldots, p_{n} \rightarrow e_{n}\right) \quad \text { if } p_{1} \text { is False } \\
\perp \quad \text { for other all situations }
\end{array}\right.
$$




\subsection{The design of integer functions using conditional forms}

Definition $1 \in$

Definition $2 \in$

Definition 3

$\in$

Definition $4 \quad \in$

Definition $5 \quad \in$

Definition $6 \quad \in$

Definition $7 \in$

Example 1: 
New Trends and Issues Proceedings on Humanities and Social Sciences.

\section{Conclusion}

\section{References}

Western Joint Computer Conference, 10,

Equation, Models and Programs.

Procedia-Social and Behavioral Sciences, 15, 